\title{
Subpopulations of Antibodies Directed Against Evolutionarily Conserved Regions of the Insulin Molecule in Insulin-Treated Patients
}

\author{
F. Karlsson, L.C. Harrison, C. R. Kahn, A. Itin and J. Roth \\ Diabetes Branch, National Institute of Arthritis, Diabetes, Digestive and Kidney Diseases, National Institutes of Health, \\ Bethesda, Maryland, USA.
}

\begin{abstract}
Summary. In the present study, we attempted to define possible subpopulations of antibodies which theoretically could be directed against evolutionarily conserved regions of the insulin molecule in sera from insulin-treated diabetic patients using a variety of labelled and unlabelled insulins which differ widely in structure but are very similar in functional properties. Ten high titre human insulin antisera from patients treated with mixed beef-pork insulin were examined. All sera were found to bind ${ }^{125}$ I-pork insulin better than labelled chicken insulin which bound better than labelled fish insulin. Detailed studies were conducted with four of the antisera using the pork and fish tracers. With two of the antisera, a subpopula-
\end{abstract}

tion of antibody could be detected with ${ }^{125} \mathrm{I}$-fish insulin which had similar affinity for both fish and pork insulin, but reacted much less well with guinea pig insulin and the desoctapeptide derivative of porcine insulin. Based on the known properties of these four insulins, the data provide suggestive evidence consistent with the hypothesis that there are subpopulations of antibodies recognizing regions on the insulin molecule that are well conserved, possibly the region involved in the formation of insulin dimers or receptor binding.

Key words: Insulin antibodies, insulin structure, evolution.
Insulin is a complex molecule which possesses multiple characteristic biological and chemical properties (Figs. 1 and 2, Table 1) [1-6]. These include specific binding to high affinity receptors on the surface of target cells, induction of specific biochemical events, (intrinsic bioactivity) [7], regulation of the concentration of insulin receptors ('down-regulation'), regulation of the affinity of insulin receptors ('negative cooperativity'), and intracellular translocation and degradation $[7,8]$. In solution, most insulins bind zinc and under appropriate conditions form dimers [4]. When injected into animals insulin is also immunogenic, stimulating the production of high titres of antibodies specific for insulin [9].

Whereas insulins of most species are very similar to one another in amino acid sequence (70-100\% homology) and can induce down-regulation, exert negative cooperativity, and are fully biologically active after binding to receptor, i. e. do not vary in intrinsic activity, chemically modified insulins and insulins of different species vary to some degree in their other properties. Insulins of different species vary over a 100 -fold range in their affinity for insulin receptors (irrespective of the species or tissue from which the receptor is derived), and some insulins do not bind zinc or form dimers (Table 1). The insulin of the Atlantic hagfish also has a slight reduction in intrinsic activity compared to binding affinity [10].

The most subtle discriminators among insulins of different species are anti-insulin antibodies. Most antibodies react with very high affinity with insulins of some species while having almost no affinity for insulins of others [9]. Because most of the antibodies studied are directed against small regions of the insulin molecule that vary from one species to another, antibodies have played only a very limited role in the assignment of conserved biological and chemical functions to specific regions of the insulin molecule.

In the present study, we have used two very different ${ }^{125}$ I-insulins (pork and fish) to explore if sera from patients immunized with beef and/or pork insulin preparations might contain small subpopulations of antibody that recognize regions of the insulin molecule that have been highly conserved during evolution. By comparing the reactivity of these antibodies with other insulins of known structure and properties, we have tentatively concluded that a subpopulation of antibodies can be detected in sera from some patients which recognize regions of the insulin molecule responsible for high affinity binding to receptor and/or dimer formation. 
STRUCTURES OF VARIOUS INSULINS

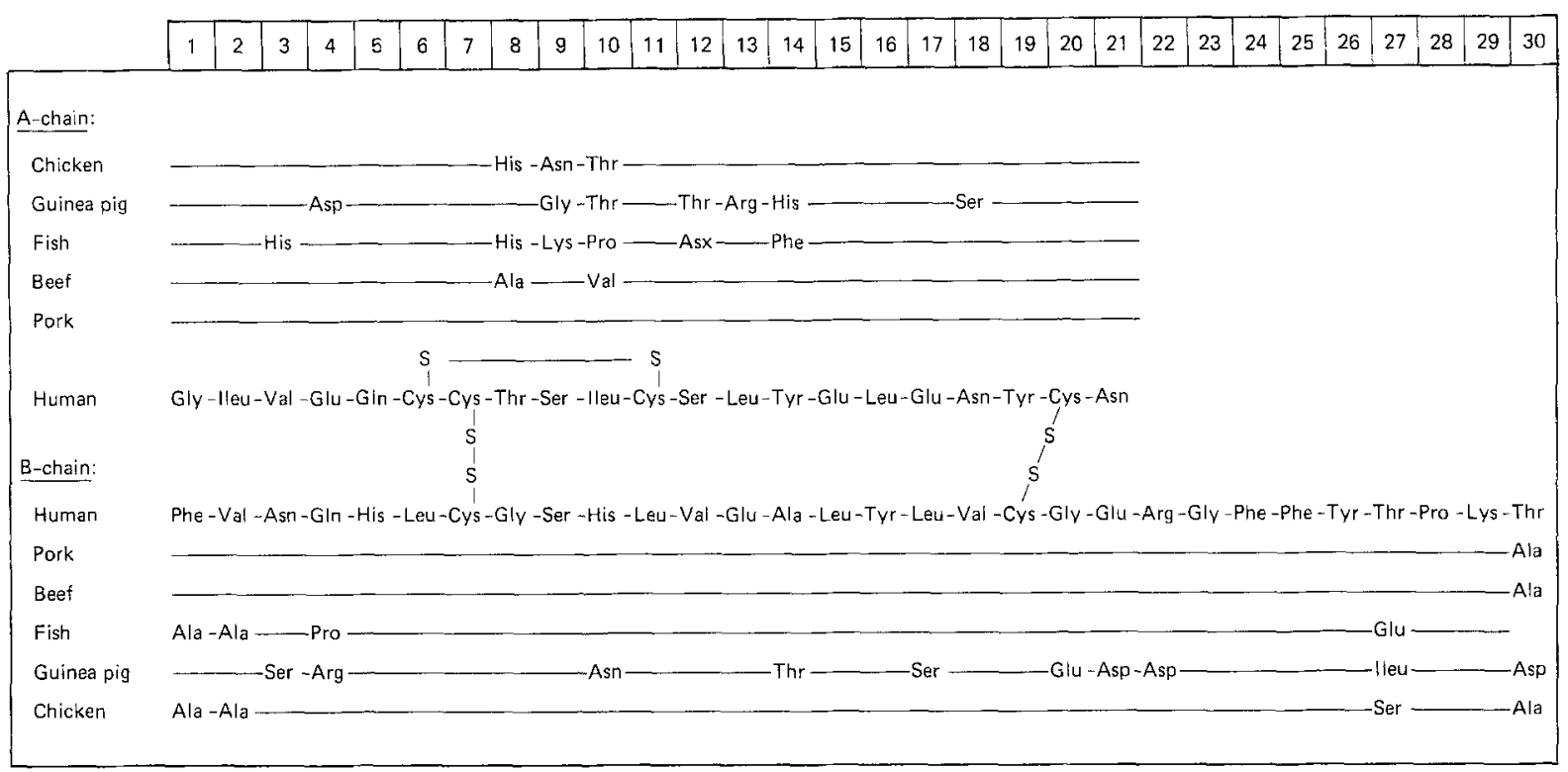

Fig. 1. The primary structures of various insulins. The complete amino acid sequence of human insulin is given as well as the residues of other insulins that differs from the basic human sequence [1]

Table 1. Properties of various insulins or insulin derivatives [1-5]

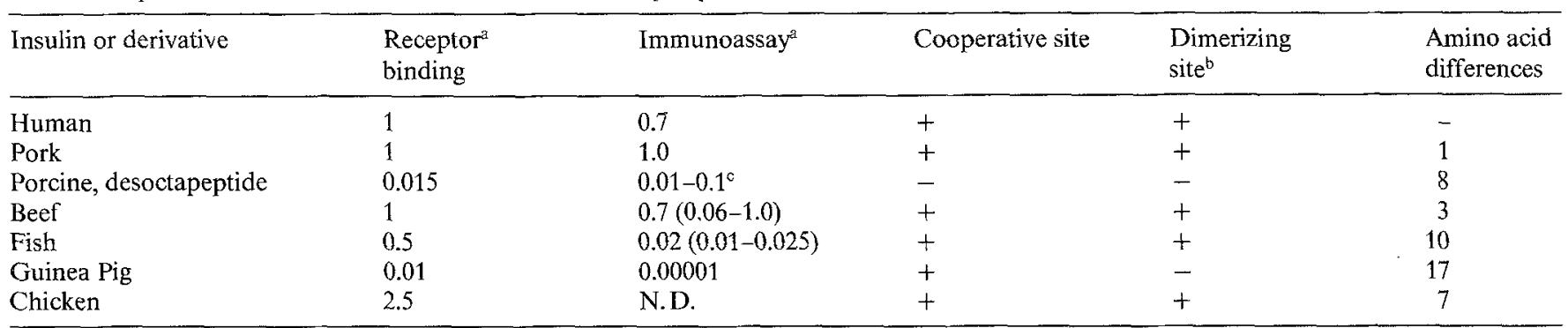

a The potencies of insulin binding to the insulin receptor or to anti-insulin antibodies are given relative to the activity of porcine insulin, expressed as the ratio of the molar concentration of porcine insulin to give $50 \%$ effect versus the molar concentration of another insulin or derivative to give $50 \%$ effect; ${ }^{b}$ The ability to bind zinc correlates in general with their ability to dimerize; ${ }^{c}$ Data from the present study

\section{Materials and Methods}

Pork insulin (24 U/mg) was purchased from Elanco Products, Indianapolis, USA. Porcine desoctapeptide (DOP) insulin (Lot 165-1082B0246), fish (bonito and tunny from Shimizu, Seiyako, Japan, Lot 615-063-300) and guinea pig insulins were kindly provided by Dr. R. E.Chance, Eli Lilly, Indianapolis. Highly purified chicken insulin was a generous gift from Dr. J. Simon, Tours, France.

Pork, fish and chicken insulins were iodinated [11] and purified as indicated in Figure 3. Since insulins may be iodinated in different sites with a resultant alteration in bioactivity and since the fish insulin used had been prepared many years ago and was rather crude, all labelled insulins were receptor-purified to ensure tracers with well preserved receptor binding and presumably bioactive determinants. For this purpose the iodinated insulins were incubated with cultured IM-9 human lymphocytes, a cell line which possesses a high concentration of insulin receptors [12]. After incubation, the cells were washed with neutral buffer to remove non-specifically bound hormone, and the bound ${ }^{125}$ I-insulin subsequently eluted with $100 \mathrm{mmol} / 1$ Hepes buffer $(\mathrm{pH}$ 6.0). The eluted hormones were then purified by gel chromatography on Sephadex G-50. These procedures resulted in improved quality of all tracers as measured by precipitation with $5 \%$ trichloroacetic acid and receptor binding (Fig. 3 ).
To determine antibody binding, aliquots of serum from insulintaking diabetic patients were diluted in normal serum (to maintain a final gamma-globulin concentration of about $1 \mathrm{mg} / \mathrm{ml}$ ) and then mixed with $4000-8000 \mathrm{cpm}$ of the various ${ }^{125} \mathrm{I}$-labelled insulin in $0.1 \mathrm{~mol} / \mathrm{I}$ phosphate buffer ( $\mathrm{pH} 7.4$ ) containing $1 \mathrm{mg} / \mathrm{ml}$ of bovine serum albumin, with or without varying amounts of unlabelled insulins. Incubations were carried out in a final volume of $0.2 \mathrm{ml}$ overnight at $4{ }^{\circ} \mathrm{C}$. Separation of antibody bound ${ }^{125} \mathrm{I}$-insulin from free insulin was achieved by polyethylene glycol (PEG) precipitation. Equal volumes of $25 \%$ (w/v) PEG 6000 in water were added, the solutions mixed and centrifuged in a Beckman microfuge (model B) for 5 min. The supernatants were aspirated and the pellets counted for radioactivity. Non-specific binding of tracer was estimated by incubation with normal human serum only and was subtracted from total tracer binding in all experiments.

\section{Results}

${ }^{125}$ I-labelled pork, chicken and fish insulin were reacted with sera from ten patients with insulin-dependent diabetes mellitus who had been treated with commercial 


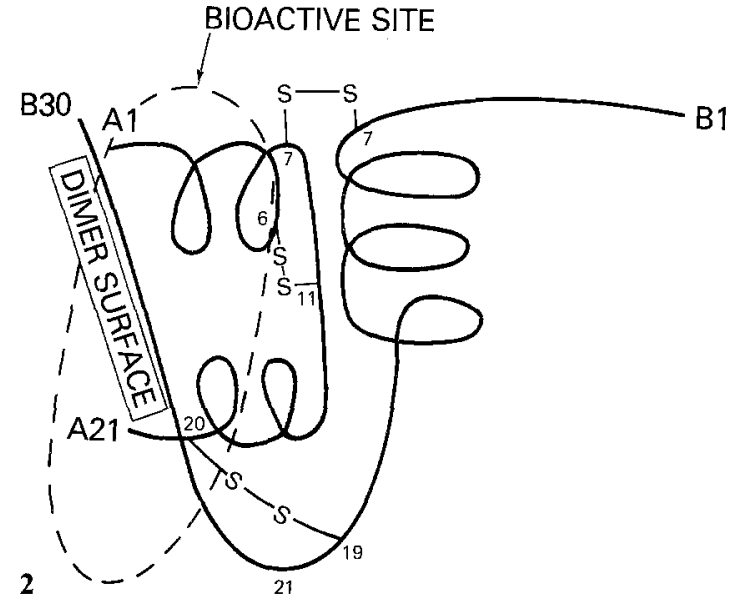

Fig. 2. A schematic representation of the polypeptide backbone of the insulin molecule. Regions involved in bioactivity and dimer formation are indicated. The drawing is based on X-ray crystallographic data of Blundell et al. [6]

Fig.3. Purification scheme of iodinated pork, chicken and fish insulins

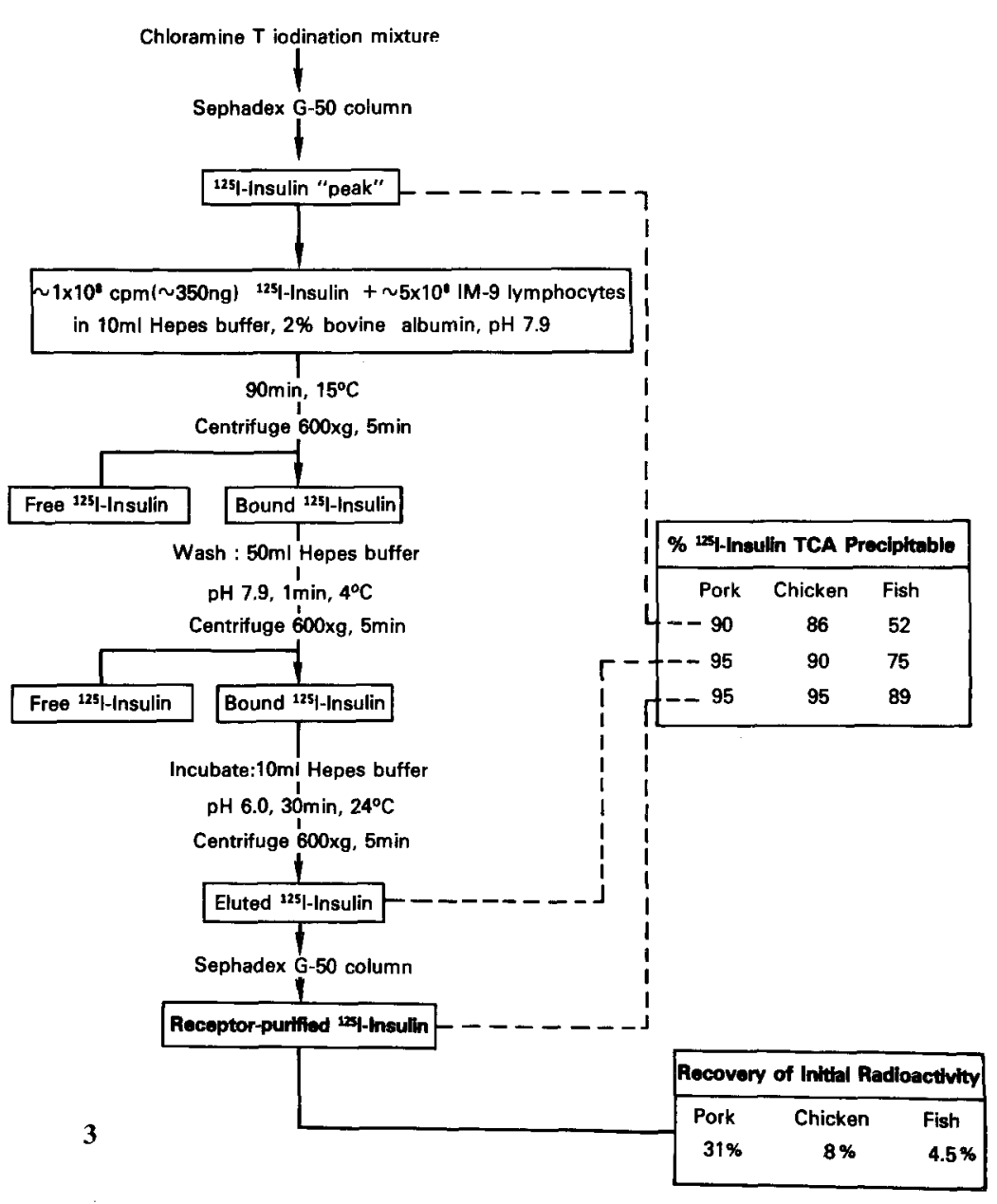

insulin (mixtures of beef and pork) and who were known to have elevated levels of antibodies to insulin by the presence of insulin resistance (five patients), allergy (three patients), or both (one patient). At a 1 to 10 dilution, all of the sera bound between 30 and $90 \%$ of the ${ }^{125} \mathrm{I}$-pork insulin. Comparing the three ${ }^{125} \mathrm{I}$-insulin tracers, all ten sera showed a similar rank order of potency: pork insulin bound better than chicken which bound better than fish (Fig. 4). This hierarchy in binding differs from that of the insulin receptor for which the relative affinities of chicken, pork and fish insulins are $2.5: 1: 0.5$ (Table 1). Thus, antibodies with receptor-like specificity, if present, could constitute only a minor fraction of the total antibody population.

Four of the sera $(1,4,6$, and 10$)$ were used for further study. Competition curves with unlabelled pork insulin were conducted over a range of concentrations from 1 to $10^{5} \mathrm{ng} / \mathrm{ml}$ (Fig. 5, left) and subjected to Scatchard analysis [13]. In these four sera, the insulin binding capacities ranged from 3 to $117 \mu \mathrm{mol} / 1$ (Table 2). All sera exhibited curvilinear Scatchard plots consistent with heterogeneity in affinity of the antibody population (data not shown). The average affinity for pork insulin for these sera ranged from $10^{-8}$ to $2 \times$ $10^{-9} \mathrm{~mol} / \mathrm{l}$ (Table 2). With these four sera, ${ }^{125} \mathrm{I}$-fish insulin bound about $10-40 \%$ as well as pork ${ }^{125}$ I-insulin (Fig.5). This suggested two possibilities - either fish insulin reacted uniformly with all of the antibodies but with $0.1-0.4$ the affinity of pork insulin, or fish insulin reacted much less well with the vast majority of antibodies but bound much more strongly to a small subpopulation of antibodies.

These possibilities could be distinguished by competition studies using unlabelled fish insulin and a porcine insulin tracer. Thus, when ${ }^{125} \mathrm{I}$-pork insulin was used as the labelled ligand (Fig. 5, left), the competition of unlabelled fish insulin was two to three orders of magnitude to the right of that by unlabelled pork insulin indicating that fish insulin has a low affinity for most of the antibodies binding pork insulin, and suggesting that there must be a subpopulation(s) of antibody with high affinity for fish insulin which accounts for the relatively high binding of the ${ }^{125} I$-fish insulin tracer.

This was substantiated by studies with ${ }^{125} \mathrm{I}$-fish insulin tracer (Fig. 5, right). With two of the sera (1 and 4), the displacement of ${ }^{125}$ I-fish insulin by unlabelled fish 


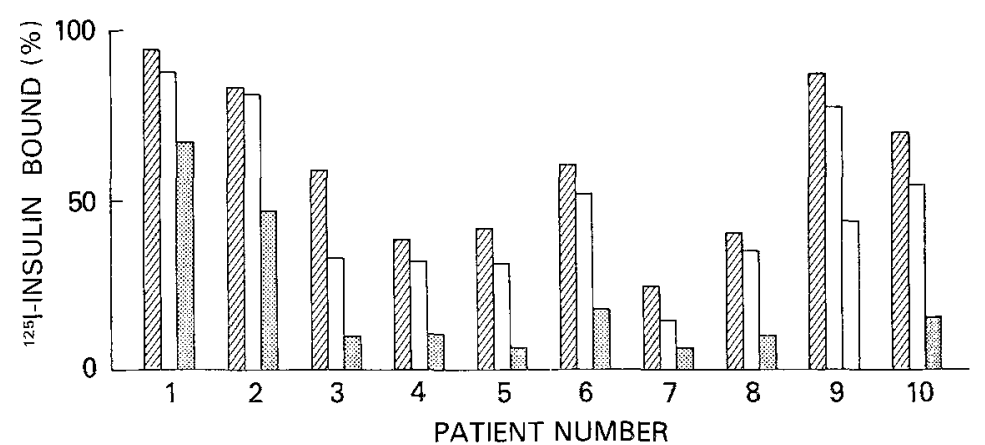

Fig. 4. Binding of tracer amounts of ${ }^{125} \mathrm{I}$-insulins to $1: 10$ dilutions of serum from insulin-treated diabetic patients. Incubations were carried out overnight with $4000-8000 \mathrm{cpm}$ of the various tracers and processed as described in the Methods section. $\otimes:{ }^{125}$ I-pork insulin, cross-hatched; $\square:{ }^{125}$ I-chicken insulin; and : : $:{ }^{125}$ I-fish insulin

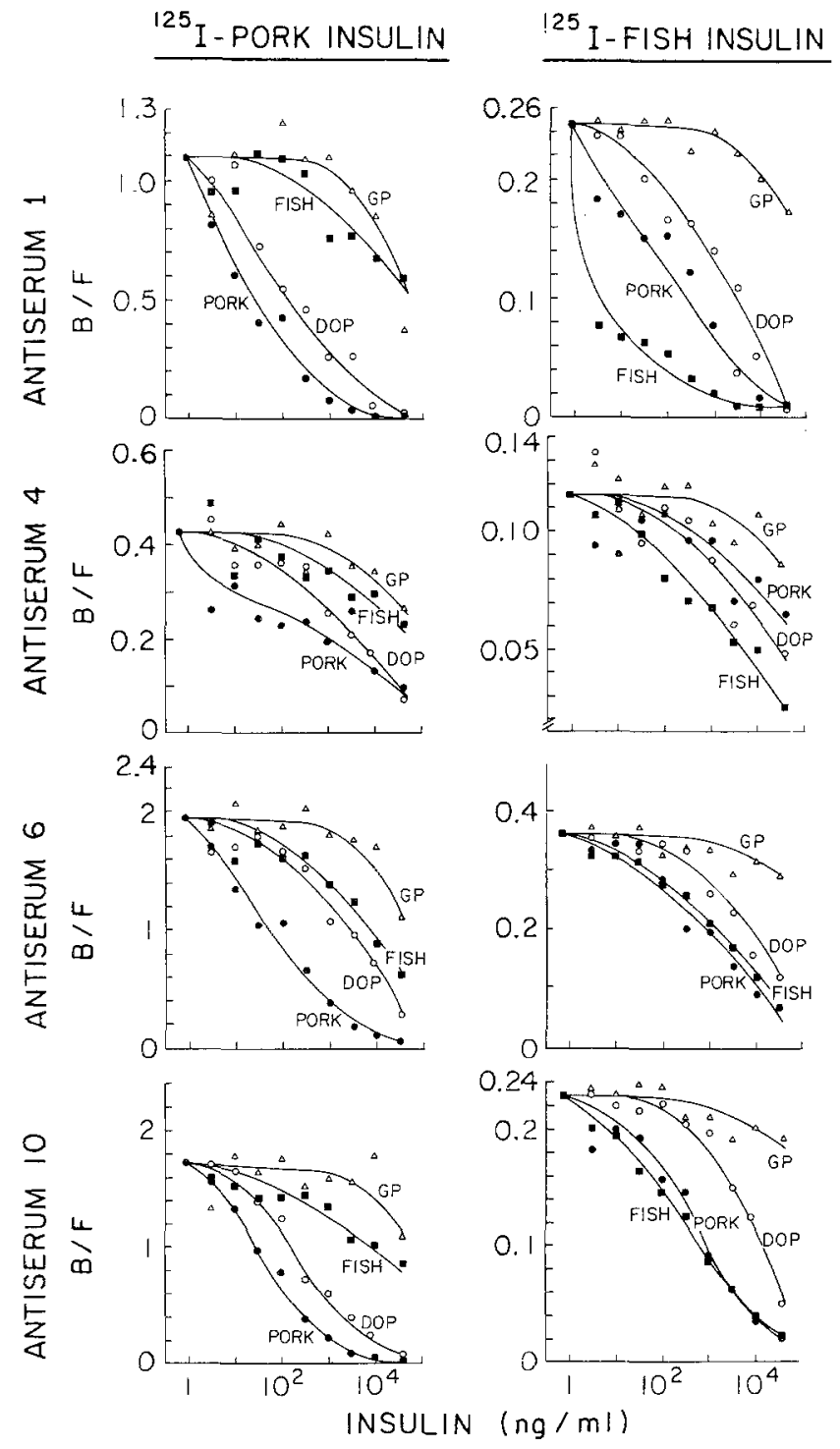

Fig. 5. Competitive binding studies to four patient sera with pork ${ }^{125} \mathrm{I}-$ insulin (left) and fish ${ }^{125} \mathrm{I}$-insulin (right) and unlabelled insulins. The ratio of bound versus free tracer $(B / F)$ is plotted on the ordinates as a function of increasing concentrations of various unlabelled hormone (pork ( ), porcine DOP $(O)$, fish $(\boldsymbol{\square})$ and guinea pig $(\Delta)$ insulins). The different sera were diluted to give comparable degrees of tracer binding insulin was even more potent than that observed with pork insulin. With the other two sera (6 and 10) the competition by fish and pork insulins were approximately equal. These data are consistent with the conclusion that the vast majority of the antibody in each serum is pork-specific, but there exists a small subpopulation of antibody that bound fish ${ }^{125}$ I-insulin with a high affinity. Since fish and pork insulins differ in eleven amino acids but are functionally very similar [1], we tentatively conclude that this subpopulation of antibodies is directed against a region of the insulin molecule which was highly conserved evolutionarily. This region could be the bioactive site, the dimer site, the zinc-binding region, the negative cooperative site or some other common region of the molecule. In an attempt to differentiate between these possibilities, competition experiments were performed with porcine desoctapeptide insulin and guinea pig insulin since these insulins differ from fish and pork insulin in these other aspects.

Desoctapeptide porcine insulin lacks eight amino acids at the carboxy-terminus of the $B$ chain, has full in-

Table 2. Insulin binding to human anti-insulin sera

\begin{tabular}{clllll}
\hline Patient & Pork & \multicolumn{3}{l}{ Fish } \\
\cline { 2 - 3 } \cline { 5 - 6 } & $\begin{array}{l}\text { Capacity } \\
(\mu \mathrm{mol} / \mathrm{l})\end{array}$ & $\begin{array}{l}\overline{\mathrm{K}}_{\mathrm{d}} \\
(\mathrm{mol} / \mathrm{l})\end{array}$ & $\begin{array}{l}\text { Capacity } \\
(\mu \mathrm{mol} / \mathrm{l})\end{array}$ & $\begin{array}{l}\overline{\mathrm{K}}_{\mathrm{d}} \\
(\mathrm{mol} / \mathrm{l})\end{array}$ \\
\hline 1 & 117 & $2 \times 10^{-9}$ & 10 & $1.7 \times 10^{-10}$ \\
4 & 7 & $1.7 \times 10^{-8}$ & 7 & $5 \times 10^{-7}$ \\
6 & 10 & $1.7 \times 10^{-8}$ & 8 & $2 \times 10^{-7}$ \\
10 & 3 & $10^{-8}$ & 3 & $8.4 \times 10^{-8}$ \\
\hline
\end{tabular}

Determinations of insulin binding capacities and average equilibrium dissociation constants $\left(\overline{\mathrm{K}}_{d}\right)$ of the different antisera were carried out by Scatchard analysis of competitive binding studies with tracer amounts of labelled pork and fish insulin and various concentrations of unlabelled pork and fish insulin, respectively. The average equilibrium dissociation constants $\left(\overline{\mathrm{K}}_{\mathrm{d}}\right)$ were derived from the hormone concentrations that produced a $50 \%$ fall in initial bound free ${ }^{125} \mathrm{I}$-insulin. [This is simply an operational construction for comparison of different antisera and used without any attempts to account for affinityheterogeneity among antibody binding sites in different sera.] 
trinsic activity when bound to receptor, but has affinity for the receptor that is only $1 \%$ that of porcine insulin. When bound to receptor DOP-insulin, however, does not induce negative cooperativity [5]. Also, this derivative differs in three dimensional folding from pork insulin and even at high concentrations in solution does not form dimers. Using the porcine ${ }^{125}$ I-insulin tracer, desoctapeptide insulin competed much more effectively than fish insulin (DOP in Fig. 5, left), supporting the conclusion that most of the antibody was recognizing determinants that were (pork) species specific and unrelated to conserved regions of biological importance. On the other hand, with fish ${ }^{125}$ I-insulin as tracer, desoctapeptide porcine insulin competed effectively (DOP, Fig. 5, right) with three of the four sera (1,6 and 10), albeit less than intact porcine insulin, suggesting that the antibodies recognized site(s) on the insulin molecule that were common to fish and intact pork insulin but were somewhat disrupted on the desoctapeptide derivative. This would include the regions on insulin responsible for affinity for receptor, cooperativity, and dimerization, but would exclude the region responsible for intrinsic activity. With serum 4, DOP insulin was equal to or slightly more effective than pork insulin in competing for fish ${ }^{125}$ I-insulin.

To characterize antibody specificity further, we studied the reactivity of guinea pig insulin in these systems. Guinea pig insulin is similar to DOP in that it has an affinity for the receptor that is $1-2 \%$ that of porcine insulin, has full intrinsic activity when bound to receptor, and does not form dimers [4]. Unlike DOP insulin, however, guinea pig insulin is fully active in inducing negative cooperativity. With pork ${ }^{125}$ I-insulin, guinea pig insulin was $1000-10,000$-fold less effective than unlabelled pork insulin in competing for binding to the four antisera (Fig. 5, left). Similarly, with three of the antisera $(1,6$ and 10$)$ inhibition in the binding of ${ }^{125} \mathrm{I}$ fish insulin by guinea pig insulin was achieved at concentrations that were three to five orders of magnitude greater than those of unlabelled fish and pork insulins. These data are consistent with the notion that the fishspecific subpopulation of antibodies recognized sites on insulin related to affinity for receptor or dimerization but not cooperativity or intrinsic activity. The reaction of fish ${ }^{125}$ I-insulin with serum 4 differed from that of the other sera in that with this serum guinea pig insulin reacted only one order of magnitude less well than pork and two orders of magnitude less well than fish.

\section{Discussion}

The presence of insulin antibodies in serum of diabetic patients treated with insulin, and particularly in patients with insulin resistance, is well established [14-16]. In the present study, sera from insulin-treated patients, i. e. immunized with mixtures of beef and pork insulin, and known to have high antibody titres were studied. As ex- pected, pork ${ }^{125}$ I-insulin bound readily to their sera. Chicken and fish ${ }^{125} \mathrm{I}$-insulins were also bound.

With the use of a purified labelled fish insulin and selected unlabelled insulins we have defined more precisely the specificity of the subpopulation of antibodies that reacted strongly with fish insulin. With two of the sera (1 and 4) unlabelled fish was about 100 times more potent than pork in inhibiting binding of labelled fish insulin, suggesting that a large fraction of these antibodies were fish-specific; that is, they did not recognize conserved regions common to the pork and fish insulin molecules. On the other hand, with two other sera 6 and 10 ), both pork and fish insulin reacted equally well and were distinctly more potent than the desoctapeptide derivative of pork insulin and guinea pig insulin, suggesting that the antibodies recognized region(s) on the insulin molecule which confer high affinity for the hormone receptor. However, the potency of guinea pig insulin was too low to be consistent with any major portion of the antibody populations to be recognizing the bioactive site. Presumably other regions of the insulin molecule were uncovered. The dimerizing site of insulin or the region responsible for negative cooperativity site [5], also seem unlikely since DOP insulin, which lacks both of these sites, displayed a considerable potency in the present experiments. One possible region which might be proposed would be B21, B22, A21. These residues would be essentially identical in fish and pork insulins, disturbed in DOP insulins and very different in guinea pig insulin (where B20 is no longer glycine and B22 becomes an aspartic acid).

Our results with pork and fish insulins are similar to those reported by Yalow and Berson [16] who found that sera of insulin-treated diabetic patients bound ${ }^{131} \mathrm{I}$ beef insulin several-fold better than ${ }^{131} I$-fish insulin, and that unlabelled fish insulin competed much less well than beef insulin for the binding of ${ }^{131}$ I-beef insulin. These findings were the experimental bases for the use of fish insulin as a therapeutic manoeuvre in insulin-resistant patients. These authors also were able to detect in sera of three insulin-resistant patients a subpopulation of antibody (by our estimate $2-5 \%$ of the total antibody) that reacted about equally well with beef and fish insulins, but did not attempt to characterize further the antigenic site.

One question remains as to why it is so difficult to find a population of anti-insulin antibodies which recognize the bioactive site of the molecule. Possibly the bioactive region of insulin, including the cooperative site, are structures against which a high degree of immunological tolerance is maintained. We also know that genetic factors influence antibody formation and that individual animals respond differently to different insulins, as well as to other antigens [17-20]. Since the number of patients investigated in the present study was small, we cannot exclude the possibility that genetically susceptible individuals may produce antibodies with receptor-like specificity for insulin. In fact, the experi- 
mental production of anti-idiotypic antibodies against insulin antibodies with insulin-like effects [21] suggests that antibodies to the bioactive site of insulin may have a receptor-like structure and could indeed exist. Such anti-idiotypic antibodies, if formed in patients, could interact with the insulin receptor and play a previously unrecognized role in the natural course of insulin resistance frequently seen in diabetic patients treated with insulin. This seems unlikely in these patients, however, since none of the sera reacted with an anti-insulin receptor serum obtained from a patient with the Type B syndrome of insulin resistance [22].

All natural antisera to insulin (and other complex molecules) are mixtures of antibodies; even our fishspecific subpopulation probably represents a mixture of antibodies that differ in affinity and specificity. Clearly, monoclonal antibodies (from hybridomas) that recognize conserved regions of insulin would be superior reagents. Since the immune response (to insulin and other molecules) is genetically determined [17-20], selection of the donor for production of hybridomas is important. The approach we describe here for the detection and characterization of subpopulations of antibody should be useful for screening of appropriate donors for such hybridoma studies.

Acknowledgments. Dr. F. A. Karlsson was a postdoctoral fellow supported by The Henning Throne-Holst Foundation. We wish to thank Dr. A. Rosenthal for providing some of the sera containing anti-insulin antibodies.

\section{References}

1. Dayhoff MO (1969) Atlas of protein sequence and structure. In: Dayhoff MO (ed) National Biomedical Research Foundation, vol 4. Silver Spring, MD, p 227

2. Freychet P, Roth J, Neville DM Jr (1971) Insulin receptors in the liver: specific binding of $\left.{ }^{125} \mathrm{I}\right]$-insulin to the plasma membrane and its relation to insulin bioactivity. Proc Natl Acad Sci 68: 1833-1837

3. Freychet $P(1976)$ Interactions of polypeptide hormones with cell membrane specific receptors: studies with insulin and glucagon. Diabetologia 12:83-100

4. Blundell TL, Wood SP (1975) Is the evolution of insulin Darwinian or due to selectively neutral mutation? Nature 257: 197-203

5. De Meyts P, Van Obberghen E, Roth J, Wollmer A, Brandenburg D (1978) Mapping of the residues responsible for the negative cooperativity of the receptor-binding region of insulin. Nature 273: 504-509
6. Blundell TL, Dodson GG, Hodgkin DC, Mercola DA (1972) Insulin-like structure in the crystal and its reflection in chemistry and biology. Adv Protein Chem 26: 279-402

7. Kahn CR (1979) What is the molecular basis for the action of insulin? Trend biochem Sci 4: 263-266

8. Gorden P (1980) Internalization of polypeptide hormones. Diabetologia 18: 263-274

9. Yalow RS, Berson SA (1961) Immunologic aspects of insulin. Am J Med 31: 882-891

10. Emdin SO, Sonne O, Gliemann J (1980) Hagfish insulin: the discrepancy between binding affinity and biologic activity. Diabetes $29: 301-303$

11. Roth J (1975) Methods for assessing immunologic and biologic properties of iodinated hormones. In: O'Malley BW, Hardman JG (eds) Methods in enzymology, vol XXXVII, part B. Academic Press, New York pp 223-233

12. Jarrett DB, Roth J, Kahn CR, Flier JS (1976) A new direct method for detection and characterization of cell surface receptors for insulin using ${ }^{125}$ I-anti-receptor autoantibodies. Proc Natl Acad Sci 73: 4115-4119

13. Scatchard G (1949) The attractions of proteins for small molecules and ions. Ann NY Acad Sci 51: 660-672

14. Lowell FC (1942) Evidence for the existence of two antibodies for crystalline insulin. Proc Soc Exp Biol Med 50: 167-172

15. Berson SA, Yalow RS, Bauman A, Rothchild MA, Newerly $K$ (1956) Insulin- ${ }^{131}$ metabolism in human subjects: demonstration of insulin-binding globulin in circulation of insulin-treated subjects. J Clin Invest 35: 170-190

16. Yalow RS, Berson SA (1964) Reaction of fish insulins with human insulin antiserums. Potential value in the treatment of insulin resistance. N Engl J Med 270: 1171-1178

17. Arquilla ER, Finn J (1963) Insulin antibody variations in rabbits and guinea pigs and multiple antigenic determinants on insulin. $J$ Exp Med 118: 55-71

18. Barcinski MA, Rosenthal AS (1977) Immune response gene control of determinant selection. I. Intramolecular mapping of the immunogenic sites on insulin recognized by guinea pig $\mathrm{T}$ and $\mathrm{B}$ cells. J Exp Med 145: 726-742

19. Rosenthal AS (1978) Determinant selection and macrophage function in genetic control of the immune response. Transplant Rev 40: 136-152

20. Keck K (1975) Ir gene control of carrier recognition. I. Immunology of bovine insulin derivatives. Eur J Immunol 5: 801-807

21. Sege K, Peterson PA (1978) Use of anti-idiotypic antibodies as cell surface receptor probes. Proc Natl Acad Sci, USA 75: 2443-2447

22. Kahn CR, Flier JS, Bar RS, Archer JA, Gorden P, Martin MM, Roth J (1976) The syndromes of insulin resistance and acanthosis nigricans. Insulin receptor disorders in man. N Engl J Med 294: $739-743$

Received: 12 August 1981

and in revised form: 23 July 1982

Dr. C.R.Kahn

Elliott P. Joslin Research Laboratory

Joslin Diabetes Center

One Joslin Place

Boston, MA 02215, USA 